\title{
Arte destacada das paredes: Galeristas roubam grafites?
}

\section{Art has been detached from the walls: Gallery owners steal graffiti?}

Marcelo Mari ${ }^{1}$ 


\section{Resumo}

No ano de 2016, a arte de rua em Bolonha foi incorporada no ritual das mostras e grandes exposições, isso vem ocorrendo no Brasil e no mundo afora. A arte de rua e sua subversão potencialmente foi enfraquecida pela necessidade de atender demandas do circuito das artes. Mas afinal como tornar um grafite imerso na cidade atrativo para galeristas? A resposta é arrancá-lo de seu lugar específico e levá-lo para o museu e depois para a galeria. Isso não é apenas um jogo de palavras, pois ocorreu recentemente na Europa e foi contestado por intelectuais, sociedade civil e artistas.

Palavras-chave: Arte Strappata; galeristas versus artista; Banksy; Blu; OsGemeos.

\section{Abstract}

In 2016, Street art was incorporated into the art system of the exhibitions and large exhibitions in Brazil and around the world. Its subversion potentiality was weakened by the need to meet new demands. Then how to make a Graffiti immersed in the city scenery attractive for the market? The answer is uproot it from its specific place and takes it to the museum and then to the gallery. This is not just a play on words; it has recently occurred in Europe and was contested by intellectuals, civil society and artists.

Keywords: Strappata art; art gallerist versus artist; Banksy; Blu; OsGemeos. 
O presente estudo tenta por luz nas relações atuais entre o papel assumido pela curadoria de exposições e os artistas, já que na contemporaneidade a curadoria e os interesses representados por financiadores das artes, coloca em lugar secundário e até mesmo irrelevante o artista e suas obras. Ocorre que isso deriva de novas relações em disputa no funcionamento do mercado de arte mundial. Até mesmo, o mais transgressor e subversivo produto de grafitagem resvala contemporaneamente nas relações mediadas do sistema da arte pela mercantilização. É justamente essa lógica que fôra denunciada pelo grafiteiro italiano Blu, a saber: o processo de mercantilização da vida. Existem limites na crítica de Blu? Certamente existem e são impostos pelo desenlace vindouro da crise iminente a médio e longo prazo entre arte e mercado.

Hoje, depois de tudo, os negociadores de arte tentam se apropriar do que antes era tido como impossível de ser institucionalizado e sacralizado no interior das instituições burguesas. Não basta dizer que a arte de rua era a última fronteira de negação da institucionalidade, pois se criaram recentemente museus a céu aberto e a própria cidade passou a ser entendida como espaço próprio da arte. Entretanto, também não basta dizer que a Street Art foi incorporada pelo circuito comercial, ou parte da produção dos artistas da arte de rua foi musealizada, mas mais ainda essa produção se tornou objeto rentável no mundo da arte contemporânea.

Não se trata aqui da encomenda de pintura de painel ou parede em casa de público consumidor de objetos conspícuos ou em galeria de São Paulo, Nova York ou Dubai, mas de processo de apropriação brutal de murais da cidade. Parece ser ideia extravagante, mas não é. Veja-se a declaração de Christian Omodeo, curador e pesquisador de arte contemporânea, corresponsável pela exposição "Street art, Banksy \& Cia. - l'arte allo stato urbano", que ocorreu na cidade de Bolonha, Itália. Essa mostra itinerante, com algumas variações, apresentada em outras capitais da Itália e da Europa, com as obras do grafiteiro inglês e as cenas locais.

Essa exposição abriu necessariamente um debate mais amplo, que já estava presente no mundo de hoje, em vários contextos muito especiais. Afinal de contas nos últimos anos, muitas fundações privadas têm se interessado cada vez mais em expor e trabalhar com artistas ou grupos de produção simbólica ou artística, que estão nos limites da cena institucionalizada. Isso ocorre como processo de alargamento das fronteiras de legitimação das práticas artísticas na contemporaneidade ou mesmo ainda como processo de incorporação de novas fronteiras. Isso dá muito a pensar, pois embora seja processo dinâmico no campo da arte contemporânea, é todo ele orientado pela centralidade do mercado de arte. Isso produz um novo regime no circuito globalizado de organização do campo das artes visuais. Se os trabalhos feitos por coletivos de artistas ou mesmo os grafites não funcionam como objeto suscetível de ser comercializado, essa realidade tem se transformado nos últimos anos. E caso não haja mesmo possibilidade de produzir valor com objetos insólitos, escassos ou transitórios, eles seguramente servirão para valorização de outros objetos mais, produzidos pelo artista ou por outros ainda, suscetíveis de adquirirem condição venal de mercadoria. O processo de estabelecimento da condição de venalidade do objeto artístico é só uma das manifestações possíveis da produção de valor na sociedade atual, cuja assimilação dos produtos simbólicos da arte contemporânea se dá de diversas maneiras na construção de universo de significados intensificadores da ano- 
mia do status quo nas sociedades psico-fisiologicamente administradas.

No caso da cena local de Bolonha, essa tem particularidade pois o graffiti e antes disso os murais, tiveram alguma expressão na cidade. Talvez porque Bolonha tenha acenado desde o período do final da segunda grande guerra até recentemente para uma tradição figurativa muito forte na arte moderna. Deixado esse parêntese de lado, o fato é que o graffiti bolonhês tem nomes expressivos entre eles Dado, Rusty e o mais famoso deles, Blu. O street artista Blu é de geração mais nova do grafite em relação aos outros dois citados. Suas pinturas estão espalhadas pela Itália, Europa e mundo.

Em 03 de janeiro de 2016, Christian Omodeo, futuro co-curador da mostra Street art, Banksy \& Cia: A arte em seu estado urbano, daria entrevista ao jornal Artribune para explicar o que estava acontecendo com a arte de rua em Bolonha. Parecia ser mais uma exposição de Street Art, com apresentação de grafites, de stickers e de colagens diversas, de assemblages e writings. De fato, a exposição poderia ser vista como um conjunto bem organizado da história das principais manifestações artísticas de rua ocorridas na cena europeia com os ratos de porão no grafite holandês dos anos de 1970, a particularidade da cena francesa com uma plêiade de grupos atuando em Paris dos anos de 1980 até hoje, a arte londrina pré e pós-grafite, a arte pop e a grafitagem norte-americana. Tudo isso somado, a expectativa era de que a exposição fosse inaugurada em março de 2016. Porém, havia nas ações dos curadores um elemento a mais, que se fosse trazido à luz como novidade no Brasil ou em outras partes do mundo levaria à aceitação ingênua, mas na Itália e especialmente em Bolonha, as coisas ganharam outra conotação. Tratava-se do empenho de se levar para a mostra alguns grafites de Blu.

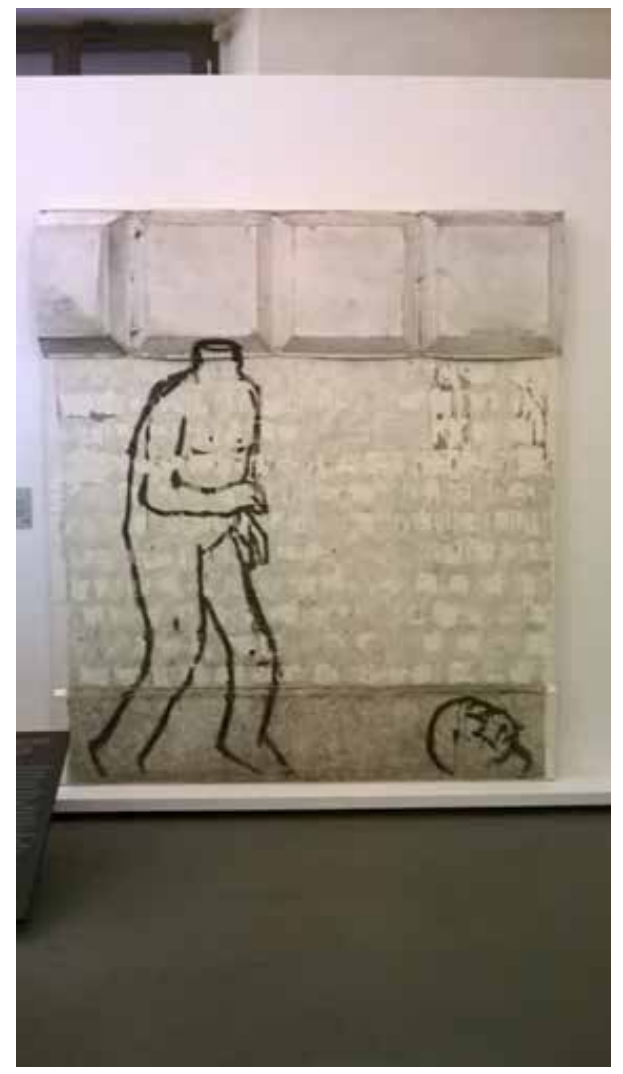

Fragmento de grafite de Blu destacado de parede e em exposição, 2016. 
Não se está falando de um convite para que o artista expusesse seus grafites, desenhos ou pinturas em outros formatos e agraciasse o público com essas obras, sejam elas telas, painéis, assemblages etc., como muitos artistas brasileiros já fizeram e continuam a fazer para ganhar dinheiros vultosos com suas obras, deixando de ser exclusivamente grafiteiros para se tornarem manipuladores de imagens em diversos suportes. Nem se tratava de apresentar fotografias e reproduções dos grafites na exposição. A intenção era levar os grafites mesmos para o interior do museu, o que foi cumprido.

De mais a mais, o debate enveredou menos para a questão da aceitação do grafite nos museus e mostras do que sobre a capacidade de resistência dessa arte contra a assimilação cultural contemporânea. É bom saber que no caso brasileiro e internacional, a tendência é justamente a mais conservadora possível de ser vislumbrada com a introdução amarga do grafite, a arte de subversão e de contestação, para a cena normalizada da vida capitalista.

Nesta situação, as produções de rua servem especialmente como o outro lado de quantidade de exposição e de promoção que garantirão ao artista, seu grau de sucesso e suas encomendas públicas e privadas futuras. Aqui opera-se na contramão da orientação subversiva do grafite que visava agir como meio e mensagem de contrapropaganda no horizonte visual, significativo e ideológico da cidade. Até aí estamos no ano de 2016, sem muita novidade no fronte desses procedimentos e aberrações que se naturalizaram e generalizaram na arte contemporânea internacional. Muitos podem contestar o fato de a inserção desses artistas grafiteiros ser em círculo mais baixo das manifestações artísticas, portanto de valorização menor no mercado de arte e abaixo daquilo que se convencionalizou como representação highbrow da pequena elite definidora daquilo que chamamos por arte contemporânea.

De fato, há conflitos entre arte institucionalizada e grafiteiros que de algum modo resistem à institucionalização. Esse processo é vivido pelo outro lado do grafite, aquele lado que não se situa como parte do processo de boa ou má inserção no circuito artístico, mas de identificação da prática da grafitagem com as atividades subversivas de construção de significado sobre a cidade. É o que asseveram Claudio Oliveira Carvalho e Carla Neves Guimarães, quando tratam da produção de escritas e imagens urbanas produzidas por jovens que lutam por seu direito à cidade:

Viver nas cidades é conviver com as segregações territoriais provocadas pela mercantilização dos espaços: quem não pode pagar é empurrado para as periferias. Os processos de urbanização nas grandes e médias cidades distanciam uma parcela significativa da população dos centros urbanos, e, consequentemente, dos serviços de saúde e saneamento básico, do acesso à educação, dos espaços de lazer e de cultura - enfim, de uma totalidade de direitos considerados básicos para todo indivíduo. Em paralelo e como reação a essa segregação sócio-espacial, insurge-se nas cidades a arte urbana, protagonizada pela juventude periférica e manifestada por um conjunto de valores, práticas e modos de vida formadores de identidades plurais, que possuem em comum a função de reivindicar espaço e visibilidade. (CARVALHO \& MARIANI, 2017)

Mas do que se tratava no caso do grafiteiro Blu? Os curadores Luca Ciancabilla e Christian Omodeo queriam levar os grafites de Blu para a exposição no formato e suporte tradicionais do grafite e isso se constituía como novidade. Os curadores da mostra de Street art em Bolonha, dois meses antes de sua inauguração, deram uma 
série de entrevistas para explicar ao público o que se estava por fazer. A intenção era utilizar o strappato para conseguir retirar os grafites de Blu de locais de Bolonha, onde supostamente os grafites estariam condenados (demolição de prédios, reformas em edifícios, mau estado de conservação dos grafites). A técnica da strappatura surgira no século XVIII para retirar pinturas murais, afrescos de igrejas medievais e obras de interesse estético ou histórico. Como se sabe essa técnica foi inventada (circa 1726-31) pelo artista de Ferrara, Antonio Contri, que usou desse procedimento engenhoso para destacar pinturas murais antigas, utilizando uma tela impregnada de solução betuminosa e solúvel em água ${ }^{1}$.

Diante da polêmica causada antes mesmo da abertura da exposição dos grafites a serem apresentados na mostra, em entrevista para o Artribune, Christian Omodeo justificava o procedimento como algo relativo ao processo de institucionalização da arte desde a formação de coleções de obras antigas em museus até o interesse recente pela preservação de grafites. Apesar da tentativa de dar normalidade ao procedimento, havia uma certa dissimulação acanhada de o fato de que as obras tinham sido retiradas da rua e dos prédios sem o consentimento do artista, justamente por ocuparem espaços que não eram lícitos em termos jurídicos, isto é, os grafites foram feitos em lugares sem a devida permissão e isso justificaria o fato de os curadores se apropriarem daqueles grafites e inseri-los na mostra e depois integrá-los à coleção pública ou privada. Se o procedimento "ilícito" do artista Blu dava oportunidade para que os seus trabalhos fossem retirados do espaço público e mesmo ainda que o grafiteiro em questão fosse processado juridicamente, o que houve de fato foi a justificação da apropriação dos grafites de Blu pelo curador-galerista a partir do fato de Blu ter se apropriado de espaços não autorizados. Tudo isso constituiu o processo de judicialização das práticas artísticas, com punições e apropriações de trabalhos artísticos como o novo foco de investigação sobre o que são os problemas principais e as problematizações inerentes da arte contemporânea.

Omodeo indagado, pelo jornalista Marco Enrico Giacomelli, sobre se havia algum sentido em destacar grafites das paredes da cidade para levá-los à exposição, respondeu:

\footnotetext{
Ha senso esporre i marmi del Partenone al British Museum o i quadri d'altare provenienti da chiese italiane nei più importanti musei stranieri? Ha senso un museo come il Quai Branly o gli oggetti che vi sono esposti dovrebbero piuttosto essere restituiti alla tribù e ai Paesi dai quali provengono? Aveva senso ridare all'Etiopia l'obelisco che si trovava a Roma, a due passi dal Circo Massimo? Come sempre, il problema vero quando si altera la destinazione d'uso di un oggetto, monumento o opera d'arte, non è tanto cosa si fa, ma perché lo si fa. Come ricorda Bénédicte Savoy, quello che va valutato non è tanto lo spostamento, ma il motivo di una "traslazione patrimoniale". Prima di tutto bisogna osservare che gli "stacchi” sono sempre esistiti. (OMODEO, 2016)
}

\footnotetext{
1 Cf. GENUS BONONIAE - MUSEI NELLA CITTÀ. Street art, Banksy \& Co. - L'arte allo stato urbano. 18 de março a 26 de junho de 2016 , Palazzo Pepoli, Bolonha, Itália, 2016.

2 GIACOMELLI, M. E. A Bologna è bufera. Sulla Street Art. Artribune. Milão, Itália, 03 de janeiro de 2016. Disponível em: <http://www.artribune.com/2016/01/ bologna-street-art-mostra-polemica/>. Acesso em: 20-03-2016. Segue tradução: "Há sentido expor os mármores do Partenon no Museu Britânico ou pinturas de altar provenientes de igrejas italianas nos mais importantes museus estrangeiros? Faz sentido um museu como Quai Branly ou os objetos nele expostos serem restituídos à tribo e aos países dos quais provém? Teria sentido devolver à Etiópia o obelisco que se encontrava em Roma, a dois passos do Circo Massimo? Como sempre o verdadeiro problema quando se altera a destinação de uso de um objeto, monumento ou obra de arte, não é tanto o que se faz, mas por que se faz. Como recorda Bénédicte Savoy, o que se avalia não é tanto o deslocamento, mas o motivo de uma de uma "traslazione patrimoniale". Antes de tudo é preciso observar que os "stacchi" sempre existiram" (tradução nossa).
} 
De fato, Omodeo referia-se ao fato de os posters de Keith Haring terem saído do subway de Nova York e foram expostos em museu, outro exemplo seria os strappati de grafites de Banksy, ocorridos os casos mais notáveis em 2007 e 2013. Em 2007, uma pequena peça de grafite destacada de muro no centro de Londres foi anunciada no site de vendas Ebay pelo preço de vinte mil libras esterlinas. Depois de protestos de pessoas que conheciam a imagem de vê-la na rua, o anúncio de venda foi retirado do site Ebay. Esse foi um episódio entre outros que sucederam com a obra de Banksy, a partir de 2007, quando sua obra já estava a valer meio milhão de libras. Em 2013, por exemplo, o grafite Slave labour (maio de 2012), feito na parede da loja Poundland, trazia imagem de menino trabalhando em máquina de costura a fazer bandeirinhas britânicas, tudo isso em clara denúncia do trabalho infantil pela rede de lojas de produtos baratos, confeccionados no exterior, em países pobres com ação e conivência imperialista. Nesse caso, a disputa, ao largo das decisões diretas de Banksy, foi travada entre a comunidade de Wood Green na Inglaterra e a Fine Art Auctions de Miami nos Estados Unidos, mais precisamente Nova York.

O mural que fora strappato, sem que ninguém percebesse, da parede de Poundland, estava à venda em site de casa de leilão nos Estados Unidos. O responsável pela Fine Art Auctions de Miami, Frederic Thut, quando indagado sobre o fato de a obra ter sido furtada de muro na Inglaterra, reservou-se o direito de apenas comentar que o grafite pertencia a colecionador privado, cujo nome por questão ética não revelaria, e não saberia o que dizer sobre o fato de aquela obra estar anteriormente na Inglaterra e estar à venda sem a permissão do artista. No final das contas, não havia como a comunidade de Wood Green reaver a obra por meios legais, pois a questão estava imbrincada na dicotomia entre lugar público e pintura não-autorizada versus interesse privado e propriedade intelectual. Restava à comunidade reaver o trabalho de Banksy, contando com ação jurídica e talvez com a chance de o artista contestar a autoria do grafite strappato. Com isso o preço de venda, pela Fine Art Auctions de Miami, desinflacionaria frente à valorização autoral.

Não foi exatamente isso que aconteceu com Slave Labour, o que levaria a supor que a obra era mesmo de Banksy e o próprio artista embora dissesse estar em desacordo com a venda de seu grafite, estava na realidade muito feliz com ela. Em outras palavras, era contra a venda, mas ganhava muito com ela. De fato, é difícil saber onde começa e onde termina a aproximação de Banksy com agentes de mercado. Isso suposto, o debate sobre a aproximação entre a arte subversiva e o mercado ganha nova conotação. Se a arte moderna, em grande parte de seus expedientes foi eminentemente crítica de sua condição de institucionalidade e sempre se manifestou como parte de processo social de negação do status quo e estabelecimento de nova realidade. Ocorre que a aproximação suposta de Banksy com o mercado nada mais é do que confundir sua possibilidade de negociação com os atores de mercado com a mutação da natureza da sociedade mercantil. Isso de fato não existiu, o que ele como artista fez foi se posicionar como agente das relações venais no interior das contradições de nossa sociedade hodierna.

Tudo leva a crer que a obra dele conta com essa maneira furtiva e anônima de especular, garantir preços elevados e completar os ciclos de valorização da arte como capital, diminuindo ao grau zero a possível dimensão contestadora da arte. Ao 
final, a controvérsia toda restou sobre a autoria do grafite. Houve especulação na época de que era mesmo de Banksy, pois havia ao lado do grafite destacado o Rat, seu símbolo-assinatura. Aliás assinatura essa deixada no muro de onde a obra fora destacada. Não por acaso, pois assim como era sabido que aquela obra era de Banksy era sabido também que se daria falta dela. $E$ a assinatura estaria ali para respaldar a autenticidade, é o que se supõe. De fato, a imprensa local acompanhou o surgimento de manifestações nas cercanias do local onde o grafite sumira e teria aparecido logo em seguida um ponto de interrogação.

Ao final de tudo, a comunidade de Wood Green entrou com queixa contra a venda do grafite strappato em leilão virtual, que foi suspenso. A obra foi então posta à venda em Londres para ser vendida, por um milhão e cem mil dólares, por Bankrobber London, através da casa de leilão Sincura Group. Esperava-se que com isso o grafite voltasse para a comunidade de Wood Green através de doação, o que não aconteceu. $O$ que se estava por fazer era uma operação que deixaria muita gente rica com arte de rua e jogaria o graffiti subversivo no interior das conservadoras instituições de arte.

Em 15 de maio de 2013, sairia entrevista no Evening Standard 3 com o diretor do Sincura Group, Tony Baxter. O debate naquele momento, um mês antes do leilão, era não exatamente sobre quem roubara o grafite e nem mesmo sobre as circunstâncias de sua volta para Londres, mas de quanto poderia ser alcançado no leilão e como talvez a obra seria ou não doada à comunidade de Wood Green. Na entrevista, Baxter refere-se ao "proprietário" do grafite que tinha posto a peça a leilão, agora para ocorrer em Londres. Em momento nenhum questionou-se o fato de a obra ter sido furtada da comunidade. A comunidade serviu de pretexto para a venda por casa de leilão em Londres, assim como o discurso da venda da obra pela casa de leilão era referendado pela ação benemérita dos ricos, a plutocracia que poderia dispor de seu dinheiro e doar a obra para a comunidade de Wood Green, onde o grafite de Banksy havia se tornado parte de percurso turístico. O leilão ocorreu e ao contrário da retórica de Baxter (que dizia que se ganharia o suficiente somente para reaver a obra, ou seja, um total de 500 mil libras), a obra rendeu o famoso milhão e cem mil dólares americanos (700 mil libras).

Ainda que infeliz a explicação de Omodeo estava muito impregnada desses precedentes quando explicou a apropriação que eles, curadores, estavam fazendo de obras do grafiteiro Blu na cidade de Bolonha. Ora, para dar um tom mais eticamente correto ao seu discurso, Omodeo e Ciancabilla faziam alusão à tentativa de preservação dos murais do grafiteiro Blu, ameaçados de destruição, pois em lugares vulneráveis. Isso garantia um verniz de falsas boas intenções para os curadores que encobria o puro interesse venal nas peças destacadas. O que se ressalta na fala de Omodeo é justamente a distância entre curadores e grafiteiros; distância que no caso de Bolonha traria grandes complicações. Amparado em Nicolas Bourriaud, dizia Omodeo:

Prima di tutto bisogna osservare che gli "stacchi" sono sempre esistiti. Pensate ai subway posters di Keith Haring, che siamo tutti contenti di vedere nelle mostre su questo artista, o agli stacchi di muri di Banksy. Ormai, ce ne sono talmente tanti che si fanno mostre - ultravisitate - solo con sue opere provenienti dalla strada. (...) Quando si parla di arte urbana, direi che il vero problema è piuttosto come

3 SHEILS, C. 'Lost' Banksy mural may fetch $£ 1$ million at London auction. Evening Standard. Londres, 15 de maio de 2013.Disponível em: <http://www.standard. co.uk/news/london/lost-banksy-mural-may-fetch-1-million-at-Iondon-auction-8616730.html>. Acesso em 03-03-2016. 
faranno gli artisti a gestire i rapporti con i curatori. Per anni, la Street Art si è sviluppata senza vere figure curatoriali. Ancora oggi, la maggior parte dei curatori di Street Art non sono altro che degli art dealer o degli organizzatori di eventi, che mettono assieme artisti senza nessun criterio e, fondamentalmente, per non dire nulla. Mi viene in mente Francesco Masci, quando scrive che assistiamo a "un'infinità di eventi, ma a nessun avvento". Per me, la sfida non è quindi tanto il diritto d'autore, ma far capire a questa comunità artistica che, oggi, esistono figure curatoriali cresciute in strada come loro e che un dialogo tra artisti e curatori urbani non è solo necessario, ma fondamentale per gli anni a venire. (...) Se espongo un'opera, perché considero che serva a portare avanti un discorso o a generare un dibattito lo faccio, esattamente come un dj che sceglie un sample per creare un pezzo totalmente nuovo. Mi aspetto di essere giudicato per quello che ho creato e non per come ho trattato i sample selezionati. (OMODEO, 2016) ${ }^{45}$

Os curadores assumem um discurso conciliatório dos interesses deles mesmos em sua posição no circuito em relação à posição dos artistas de rua (Street Artists). Esse tom conciliatório serve para justificar a apropriação de grafites do artista Blu sem seu consentimento e também para justificar a possível venda desses trabalhos no mercado de arte e a partilha entre curador e artista, frente ao fato de que a arte de rua pode ser apropriada por interesse particulares ou furtada de seu lugar de significação para a coletividade na tessitura social. Nesse sentido, o curador Omodeo justificaria sua posição de Curador, como parte do circuito da arte em busca de oportunidades de mercado, assim como o artista. A significação disso é muito clara, em um ambiente altamente competitivo como o da arte de rua, mas também da arte contemporânea, com poucas oportunidades para artistas e curadores, resta a concorrência geral para a sobrevivência em um sistema marcado pela ideia de exceção e aparências:

Se poi uno o più artisti sentiranno il bisogno di fare ricorso a un quadro giuridico sclerotizzato come il diritto d'autore, valuterò il da farsi, ma la mia posizione non cambierà: un artista che rifiuta che la sua opera possa essere usata, trasformata, distrutta/conservata o deturpata è e sarà sempre ai miei occhi come una multinazionale che tutela i propri prodotti. Personalmente, ho altre priorità, come affermare che non ci vedo nulla di male a prendere dei muri di proprietà di un privato e trasformarli in bene comune, perché si fa l'esatto contrario di quello che si è fatto fino ad oggi, o valutare con dei giuristi se è teoricamente possibile imporre per legge a chiunque si appropri, legalmente o meno, di un'opera d'arte in strada di versare il 50\% del ricavato in caso di un'eventuale vendita all'artista che l'ha prodotta. Questo sì che scoraggierebbe il mercato degli street pieces. (OMODEO, $2016)^{6}$

\footnotetext{
4 GIACOMELLI, M. E. A Bologna è bufera. Sulla Street Art. Artribune. Milão, 03 de janeiro de 2016. Disponível em: <http://www.artribune.com/2016/01/bologna-street-art-mostra-polemica/>. Acesso em: 20-03-2016.

5 "Antes de tudo é preciso observar que os 'destacamentos' sempre existiram. Pensem nos subway posters de Keith Haring, que estamos todos felizes de ver nas exposições sobre esse artista, ou às obras destacadas de muros de Banksy. Ainda mais que hoje, são tantas obras que se fazem exposições - ultra-visitadas - só com obras provenientes das ruas. (...) Quando se fala de arte urbana, diria que o verdadeiro problema é antes como farão os artistas para gerir relações com os curadores. Por anos, a Street Art se desenvolveu sem verdadeiras figuras curatoriais. Ainda hoje, a maior parte dos curadores de Street Art não são outros que os marchands ou os organizadores de eventos, que colocam juntos artistas sem nenhum critério e, fundamentalmente, para não dizer nada. Me vem à mente Francesco Masci, quando escreve que assistimos a "uma infinidade de eventos, mas a nenhum acontecimento". Para mim, o desafio não é então tanto o direito do autor, mas fazer a comunidade artística entender que, hoje, existem figuras curatoriais crescidas por assim dizer 'na estrada' como eles e que um diálogo entre artistas e curadores urbanos não é só necessário, mas fundamental para os anos que virão. (...) Se exponho uma obra, porque considero que sirva para levar adiante um discurso ou gerar debate o faço exatamente como um $\mathrm{Dj}$ que escolhe um sample para criar uma parte totalmente nova. Espero ser avaliado por aquilo que criei e não por como tratei os samples selecionados." (tradução nossa).

6 GIACOMELLI, M. E. A Bologna è bufera. Sulla Street Art. Artribune. Milão, 03 de janeiro de 2016. Disponível em: <http://www.artribune.com/2016/01/bologna-street-art-mostra-polemica/>. Acesso em: 20-03-2016. Diz Omodeo: "Se de agora em diante um ou mais artistas sentirão a necessidade de fazer recurso a um quadro jurídico esclerosado como o direito autoral, avaliarei como algo a se fazer, mas minha posição não mudará: um artista que nega que sua obra possa ser usada, transformada, destruída/conservada ou deturpada é e será sempre aos meus olhos como uma multinacional que tutela os próprios produtos. Pessoalmente, tenho outra prioridade, como aquela de afirmar que não vejo nada de mal em compreender os muros de propriedade privada e transformá-lo em bem comum, porque se faz assim o contrário daquilo que se tem feito até agora, ou se avalia com juristas se é teoricamente possível impor por lei a qualquer um que se aproprie, legalmente, de uma obra de arte de rua de versar $50 \%$ do arrecadado em caso de venda para o artista que a produziu. Isto encorajaria o mercado da arte de rua." (tradução nossa).
} 
O grafiteiro Blu fez pinturas no Brasil em 2009. Sua obra também é conhecida em outros países latinos, especialmente Argentina e México. Quando da exibição de suas obras arrancadas dos muros da cidade para a exposição organizada por Luca Ciancabilla e Christian Omodeo, Blu resolveu apagar todos os seus grafites em Bolonha. Sua resposta era contra a arte de rua privatizada. Naquela ocasião, mais precisamente à véspera da abertura da exposição de Street Art em Bologna, em nova entrevista aos jornais o curador Christian Omodeo comentaria com arrogância o seguinte sobre a atitude contestatória do artista que resolvera apagar todos seus grafites na cidade de Bolonha: "Non è l'unico ad avere il diritto di decidere sulla vita della propria opera. E gli abbiamo restituito quella carica di dissenso che non aveva più...".(SMARGIASSI, 13-03-2016 ${ }^{7}$

O que causa estranheza na argumentação de Omodeo é seu autoritarismo em dizer que o artista que concebeu e executou o grafite nas paredes da cidade, já não pode decidir o que será feito com sua obra. Segundo o curador, ela já não mais the pertence. Pertence então à cidade? Não, a resposta não é exatamente essa. $O$ fato é que para o curador da mostra, que retirou trabalhos de Blu da rua para expô-los no museu sem o consentimento do artista, as obras de Blu não são mais dele não é afirmação simples, poética e enlevada de que a obra tem múltiplos significados e que ganha autonomia em relação ao seu idealizador. Nada disso, é a afirmação judicial de que $o$ artista por pintar em lugares da cidade privatizada que não lhe pertencem, abre o flanco para que a sua obra possa ser pilhada por outros.

Esses outros podem ser tanto quanto as apropriações que se fazem sobre os grafites por outros grafiteiros e pichadores, o picho do picho, quanto como agora a mais nova fonte inexplorada da arte contemporânea que são as apropriações de muros por gente ligada a galerias, feiras e bolsas de arte. Omodeo deixou claro que as obras de Blu eram passíveis de serem apropriadas pelos homens de mercado, independentemente de sua vontade, sem que precisassem pagar qualquer coisa para o artista e bastando entrar em acordo com o dono do espaço onde o grafite foi feito.

O artista foi visto, no caso descrito acima, como alguém que não estava comprometido com o sistema artístico e o ciclo vigente desse sistema, que deve ter sua etapa final de sacramentação e de necessária valorização comercial do produto, e justamente por isso Blu deve ser considerado, malgrado tudo que fez, como alguém que deve ser deletado do sistema. Ou se está dentro desse sistema, ou se está fora; Não havendo outra opção. Essa alternativa embora metafórica determinou o lugar de fala do curador em relação ao artista. O curador tornou-se uma espécie de algoz e bom representante da distopia contemporânea, em que a redução imanente de realidade se dá nos braços da mercantilização e privatização de tudo.

Essa situação gera dois outros significados subentendidos: 1) O curador chegou a afirmar que dentro do sistema contemporâneo de arte, que inclui também um setor específico de discussão jurídica de direitos autorais e de uso de imagens etc., os atores, os entes e o sistema deles como um todo se auto justificam; concluir-se-ia com isso que cumpridas as funções parcas das partes, elas se tornam irrelevantes, mas

7 SMARGIASSI, M. Blu, il curatore della mostra: "Ora le sue opere sono soltanto al museo". La Repubblica. Bolonha, 13 de março de 2016. Disponível em: <http://bologna.repubblica.it/cronaca/2016/03/13/news/blu_il_curatore_della_mostra_ora_le_sue_opere_sono_soltanto_al_museo_-135360267/>. Acesso em: 20-04-2016. 
o que o funcionamento do circuito demonstra é que o artista está refém não só do circuito, mas e principalmente dos curadores e especialistas que hoje trabalham com uma visão muito específica de negócios na arte no estrito senso das relações de produção e de consumo no capitalismo; as ameaças dos curadores da mostra em Bolonha ao artista Blu demonstram o grau de baixeza a que estas chantagens de mercado podem chegar. 2) A irrelevância do artista e do significado da obra são decretados pelo funcionamento da lógica de valorização e desvalorização proposta pelo jogo dos atores e entes envolvidos no sistema da arte. O problema é justamente esse, hoje parece não haver arte que não seja passível de algum tipo de comercialização, em suas expressões mais torpes a lógica do mercado de arte atual quer incorporar todas as expressões sejam mais avançadas ou não da pesquisa artística contemporânea.

Essa dimensão contemporânea da arte enfraqueceu sua mensagem de transformação, de mudança e de liberdade. Isso se deve ao fato de que o mercado está a buscar continuamente novos horizontes de especulação, com tudo o que isso significa de aposta na propaganda massiva e na publicidade de características diferenciadoras de determinado produto artístico em comparação com outros. É justamente esse Plus fictício de sentido, de experiência, de raridade e de outros qualificativos que transformam o produto artístico em algo se não mais aprazível, pelo menos mais interessante para o consumo diferenciado.

O grafiteiro Blu tomou a atitude anticapitalista e corajosa na contracorrente da realidade do sistema das artes na lógica neoliberal, de apagar seus grafites ou "murales" como são conhecidos na Itália. A questão foi melhor colocada pelo jornal II Fatto Quotidiano que toca no ponto central da polêmica, a saber, a autorização dos artistas:

Sta facendo discutere - e a ragione - la decisione di Genus Bononiae, una delle più prestigiose istituzioni culturali bolognesi di esporre in un museo alcuni murales realizzati su pareti e facciate di edifici, pubblici e privati, del capoluogo emiliano. Ma non è solo la scelta di fare della c.d. street art il tema di un'esposizione museale, "normalizzando" così un genere artistico "ribelle" a far discutere, quanto quella di realizzare l'esposizione rimuovendo fisicamente dagli edifici sui quali gli artisti le hanno realizzate le opere d'arte in questione senza chiedere nessun permesso o autorizzazione ai loro autori. (SCORZA, 2016) ${ }^{8}$

Auxiliado por pessoas dos Centros Sociais de Bolonha (espécie de pontos de cultura da cidade), Blu - considerado um dos dez mais importantes grafiteiros do mundo - apagou todos seus grafites da cidade de Bolonha. O jornal $A$ Repubblica transcreveu trechos de entrevista de Blu ao Blog Giap (pois o artista não dá entrevista à grande mídia). Blu foi peremptório em dizer o que estava por trás daquela ação dos curadores, que se autodenominaram a salvaguarda de suas obras para a posteridade a partir da institucionalização:

La mostra "Street Art" è il simbolo di una concezione della città che va combattuta, basata sull'accumulazione privata e sulla trasformazione della vita e della creatività di tutti a vantaggio di pochi. Di fronte alla tracotanza da landlord, o

\footnotetext{
8 SCORZA, G. Bologna, i murales finiscono al museo senza il permesso degli artisti. II Fatto Quotidiano. Roma, 06 de janeiro de 2016 . Disponível em <http://www. ilfattoquotidiano.it/2016/01/06/bologna-i-murales-finiscono-al-museo-senza-il-permesso-degli-artisti/2352753/>. Acesso em: 10-05-2016. Blu "está colocando em discussão e com razão a decisão de Genus Bononiae, uma das mais prestigiosas instituições culturais bolonhesas, de expor em um museu alguns grafites realizador sobre paredes e edifícios, públicos e privados, da capital da Emilia Romana. Todavia não é só a escolha de fazer da dita street art o tema de uma exposição museal, "normalizando" assim um gênero artístico "rebelde" para possível debate, mas também aquela ação de realizar a exposição removendo fisicamente dos edifícios sobre os quais os artistas tinham feito suas obras sem pedir nenhuma permissão ou autorização aos seus autores. " (tradução nossa).
} 
da governatore coloniale, di chi si sente libero di prendere perfino i disegni dai muri, non resta che fare sparire i disegni. Agire per sottrazione, rendere impossibile l'accaparramento. Non stupisce che ci sia l'ex-presidente della più potente Fondazione bancaria cittadina dietro l'ennesima privatizzazione di un pezzo di città. Questa mostra sdogana e imbelletta l'accaparramento dei disegni degli street artist, con grande gioia dei collezionisti senza scrupoli e dei commercianti di opere rubate alle strade. Non stupisce che sia l'amico del centrodestra e del centrosinistra a pretendere di ricomporre le contraddizioni di una città che da un lato criminalizza i graffiti, processa writer sedicenni, invoca il decoro urbano, mentre dall'altra si autocelebra come quella della street art e pretende di recuperarla per il mercato dell'arte (SMARGIASSI, 12-03-2016) ${ }^{9}$.

As palavras de Blu são fortes e cheias de sentido, ou seja, a mostra de grafite em Bologna nada mais é do que um modo de proceder do sistema da arte vinculado exclusivamente à acumulação capitalista e em benefício de pouquíssimos. Para o artista restava, frente aos mandos e desmandos dos donos da terra e autoridades políticas inescrupulosas, "destruir" sua própria arte, apagar sua arte dos muros da cidade. 0 pior de tudo isso é a ausência de perspectiva de horizontes outros para o sistema da arte em Bolonha na esteira da tendência internacional, por isso Blu se queixa da postura similar da centro-esquerda e dos governos de centro-direita em Bolonha, todos rezando a cartilha neoliberal que, por um lado, criminaliza os jovens writers, por outro, aposta na arte como grande negócio.

A exposição "Street art, Banksy \& Cia. - A arte em seu estado urbano" foi montada como uma maneira a apresentar os grandes nomes do graffitti mundial, entre eles: principalmente, Banksy, Dran, Blu e também OsGemeos. A abordagem da exposição é justamente legitimar o grafite na lógica de uma exposição convencional de museu. Tanto esse é o conceito básico que, a maior parte das obras expostas eram de coleções privadas ou de galerias especializadas em venda de Street Art. Retiradas de seu lugar na trama urbana, os grafites perdem sua força de contraposição às mensagens reificadas da cidade venalizada e não servem como contrapropaganda de mensagens liberatórias do processo de redução unidimensional da vida.

Era justamente esse o impasse colocado por Blu, pois na medida em que o grafite se insere no universo convencional da arte institucionalizada de hoje, os grafiteiros tornam-se parte do processo de destruição da potencialidade crítica de sua própria arte. Com OsGemeos, a domesticação do grafite não ocorreu de maneira diversa da que ocorreu com Banksy, embora eles todos neguem esse processo nefasto. Nas obras de OsGemeos a assimilação e domesticação dos elementos outrora críticos da sociedade revelam que o mercado soube ser mais subversivo do que os grafiteiros e os incluiu no processo de conscientização das derrotas sofridas pela arte de contestação social. Em tudo hoje as obras de Banksy e de OsGemeos se parecem com obras de arte convencionais no circuito convencional das artes. No caso especí-

\footnotetext{
9 SMARGIASSI, M. Bologna, Blu cancella tutti i suoi murales: "No alla street art privatizzata". La Repubblica. Bolonha, 12 de março de 2016. Disponível em: <http:/l bologna.repubblica.it/cronaca/2016/03/12/news/bologna_graffiti-135303806/>. Acesso em: 10/05/2016. Segue tradução: "A exposição "Street Art" é o símbolo de uma concepção da cidade que está sendo combatida, baseada sobre a acumulação privada e sobre a transformação da vida e da criatividade de todos em vantagem de poucos. Diante da arrogância do landlord, ou do alcaide colonial, de que se sente livre mesmo de tomar os desenhos dos muros, não resta outra coisa a não ser fazer desaparecer os desenhos. Agir por subtração, tornar impossível a acumulação. Não causa espanto que seja o ex-presidente da mais potente fundação bancária a estar por trás da enésima privatização de parte da cidade. Esta exposição de desembaraço aduaneiro e de açambarcamento de desenhos de artistas de rua, é para o deleite de colecionadores e comerciantes, sem escrúpulos, de obras roubadas nas ruas. Não surpreende que seja o amigo da centro-direita e da centro-esquerda a fingir conciliar as contradições de uma cidade que, por um lado criminaliza os grafites, processa jovens writers, invocando o decoro urbano , enquanto por outro lado se auto-celebra como a cidade da Arte de Rua e pretende recuperá-la para o mercado de arte".
} 
fico de OsGemeos, eles têm trabalhado com objeto e pinturas no sentido de reforçar a diferença entre arte de museu e arte de rua. Veja-se por exemplo a obra Madonna com bambino (2000) ou The Guitar (2007), que brincam com a linguagem das artes visuais de museu e mostram que a linguagem do grafite funciona em outro lugar, na rua. Isso sem romper com o esquema conservador da arte atual.

\section{Referências}

BANKSY. Wall and Peace. London: Century, 2005.

BOURRIAUD, N. Postproduction - La culture comme scénario: comment l'art reprogramme le monde contemporain. Dijon: Les Presses du réel, 2004.

CARVALHO \& MARIANI. Escritas marginais nas ruas: expressões do direito visual à cidade In Revista de Direito da Cidade vol. 09, nํ 3, 2017.

GENUS BONONIAE - MUSEI NELLA CITTÀ. Street art, Banksy \& Co. - L'arte allo stato urbano. 18 de março a 26 de junho de 2016, Palazzo Pepoli, Bolonha, Itália, 2016.

GIACOMELLI, M. E. A Bologna è bufera. Sulla Street Art. Artribune. Milão, Itália, 03 de janeiro de 2016. Disponível em: <http://www.artribune.com/2016/01/bologna-street-art-mostra-polemica/>. Acesso em: 20-03-2016.

IRVINE, M. The work on the Street: Street art and Visual Culture In HEYWOOD, I. (org.). The handbook of visual culture. London: Berg Publishers, 2012.

KNIGHT, C. K. Public Art: Theory, practice and populism. Malden: Blackwell Publishing, 2008.

MARICATO, Ermínia. Metrópole na Periferia do Capitalismo: ilegalidade, desigualdade e violência. São Paulo: Editora Hucitec, 1996.

RANCIERE, J. A partilha do sensível: estética e política. São Paulo: Editora 34, 2005.

SCORZA, G. Bologna, i murales finiscono al museo senza il permesso degli artisti. Il Fatto Quotidiano. Roma, 06 de janeiro de 2016. Disponível em <http://www.ilfattoquotidiano.it/2016/01/06/bologna-i-murales-finiscono-al-museo-senza-il-permesso-degli-artisti/2352753/>. Acesso em: 10-05-2016.

SMARGIASSI, M. Blu, il curatore della mostra: "Ora le sue opere sono soltanto al museo". La Repubblica. Bolonha, 13 de março de 2016. Disponível em: <http://bologna.repubblica.it/cronaca/2016/03/13/news/blu_il_curatore_della_mostra_ora_le_ sue_opere_sono_soltanto_al_museo_-135360267/>. Acesso em: 20-04-2016. 
SMARGIASSI, M. Bologna, Blu cancella tutti i suoi murales: "No alla street art privatizzata". La Repubblica. Bolonha, 12 de março de 2016. Disponível em: <http://bologna. repubblica.it/cronaca/2016/03/12/news/bologna_graffiti-135303806/>. Acesso em: $10 ; 05 ; 2016$. 